\title{
Reduction of $\beta$-Chlorovinylaldehydes with Zinc Powder
}

\author{
Akira Hara and Minoru Sekiya \\ Shizuoka College of Pharmacy $\mathbf{1}$
}

(Received August 2, 1971)

\begin{abstract}
Treatments of $\beta$-chlorovinylaldehydes with zinc powder in ethanol selectively remove the $\beta$-chlorine atom to give the $\alpha, \beta$-unsaturated aldehydes. However, the same treatments in nitrogen atmosphere and, preferably, by using the activated zinc powder lowered remarkably the yield of the $\alpha, \beta$-unsaturated aldehydes and give the reductive dimer, 1,2 -di(1-alkenyl)ethylene glycol, as major product.
\end{abstract}

Since easy preparation of $\beta$-chlorovinylaldehydes has been introduced by the reaction of aliphatic and alicyclic ketones ${ }^{2}$ or ethynyl compounds ${ }^{3}$ with Vilsmeier reagents, a number of papers on the reactions of $\beta$-chlorovinylaldehydes has been published, most of which involve substitution reaction of the $\beta$-chlorine atom by nucleophiles such as amines. ${ }^{4)}$ However, there has been no report on hydrogen-substitution of the chlorine atom of the $\beta$-chlorovinylaldehydes which are conjectured to show more complication to reduction, because they have not only olefinic double bond but also readily reducible formyl group in the molecule. We have now found that this selective hydrogen-substitution can be performed by reduction of ethanolic solution of $\beta$-chlorovinylaldehyde with zinc powder under requisite condition to give the $\alpha, \beta$-unsaturated aldehyde, but this reaction tends to form the reductive dimer, $1,2-$ di(1-alkenyl)ethylene glycol, by carrying out the reaction under nitrogen atmosphere and, preferably, with the activated zinc powder. We wish to report our investigation on these and related reactions.

It was indicated that, when an ethanolic solution of 2-chloro-1-cyclohexenealdehyde (1) was refluxed along with zinc powder, the reduction proceeded to give 1-cyclohexenealdehyde (2) which was identified as the 2,4-dinitrophenylhydrazone. The presence of water seemes necessary for this reaction, if water acts as hydrogen donor. By detailed examination of the effect of the presence of water on the yield the highest yield of the product was obtained by using $96.5 \%$ ethanol. Use of more and less amount of water showed much decreased yield of the product. We extended this reaction to the other analogous $\beta$-chlorovinylaldehydes, $\alpha$-methyl- $\beta$-chlorocinnamaldehyde (3), 2-chloro-1-cyclopentenealdehyde (4), and $\alpha$ - $n$-pentyl$\beta$-chlorocrotonaldehyde (5), which were prepared from the corresponding ketones by the reaction with dimethylformamide-phosphoryl chloride reagent. The last one, which have not been known, was obtained as a crude oil of $80 \%$ purity, because of unavoidable decomposition in purification. Identity of this material was made by converting to the 2,4-dinitrophenylhydrazone. The reductions of these $\beta$-chlorovinylaldehydes were carried out under the selected conditions of using $96.5 \%$ ethanol and $1 / 9$ molar proportion of the substrate to zinc powder. Results of the experiments are summarized in Table I. In every runs of these, the corresponding $\alpha, \beta$-unsaturated aldehydes were obtained as volatile liquids, which were identi-

1) Location: 2-2-1, Oshika, Shizuoka.

2) a) Z. Arnold and J. Zemlicka, Proc. Chem. Soc., 7, 227 (1958); b) Idem, Coll. Czech. Chem. Commun., 24, 2385 (1959).

3) W. Ziegenbein and W. Franke, Angew. Chem., 71, 573 (1959).

4) Z. Arnold and J. Zemlicka, Coll. Czech. Chem. Commun., 24, 2378 (1959); J. Bodendorf and R. Mayer, Chem. Ber., 98, 3561 (1965); J.M.F. Gogan and D. Lloyd, Chem. Commun., 1967, 1043; S. Hauptmann, M. Weissenfels, M. Scholz, E.M. Werner, H.J. Kohler, and J. Weisflog, Tetrahedron Letters, 1968, 1317. 
TABLE I. The Reduction ${ }^{a)}$ to $\alpha, \beta$-Unsaturated Aldehydes

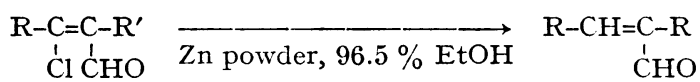

\begin{tabular}{|c|c|c|c|c|}
\hline \multirow{2}{*}{$\mathrm{R}$} & \multirow{2}{*}{$\mathrm{R}^{\prime}$} & \multicolumn{2}{|c|}{ Reaction condition } & \multirow{2}{*}{$\begin{array}{l}\left.\text { Yield }{ }^{b}\right) \text { of } \alpha, \beta \text { - } \\
\text { unsaturated } \\
\text { aldehyde }(\%)\end{array}$} \\
\hline & & Temp. & Time (hr) & \\
\hline \multirow{3}{*}{$\mathrm{C}_{6} \mathrm{H}_{5}$} & $\mathrm{CH}_{3}$ & $62-65^{\circ}$ & 1.5 & 49.2 \\
\hline & & reflux & 1.5 & 65.2 \\
\hline & & reflux & 1.0 & $37.3^{c)}$ \\
\hline $\mathrm{CH}_{3}$ & $n-\mathrm{C}_{5} \mathrm{H}_{11}$ & reflux & 3.0 & 42.0 \\
\hline
\end{tabular}

a) Substrate 0.05 mole, zinc powder $0.45 \mathrm{~g} \cdot$ atom and $96.5 \%$ EtOH were used.

$b$ ) Yield is calculated from peak area of gas chromatogrum of the crude distillate of the product.

c) 1,2-Di(1-cyclopentenyl)ethylene glycol $(0.05 \mathrm{~g}, 0.03 \%$ yield) was obtained as byproduct.

fied as the known 2,4-dinitrophenylhydrazone or semicarbazone. Their yields were calculated from the peak area of the gas chromatogrum because of laboriousness of purification.

In the study on the reaction condition, it was found that, when the reaction was carried out in nitrogen atmosphere and, preferably, the zinc powder was activated by rapid washing with diluted hydrochloric acid, the yield of the $\alpha, \beta$-unsaturated aldehydes was decreased in great deal, and the reductive dimer, 1,2-di(1-alkenyl)ethylene glycol, was produced instead. That is, when the compound, 1 , dissolved in $96.5 \%$ ethanol was refluxed in nitrogen atmosphere along with the activated zinc powder, 1,2-di(1-cyclohexenyl)ethylene glycol(6) was obtained in $44 \%$ yield. Observed nuclear magnetic resonance (NMR) spectrum of this material was interpreted to fit the structure by the following assignments: the multiplet at $\tau 4.25$ to the two olefinic hydrogens, the singlet at $\tau 6.1$ to the two methyne hydrogens, and the singlet at $\tau 7.64$ to the two hydroxyl hydrogens. This material also showed positive periodic acid color reaction ${ }^{5)}$ characteristic of 1,2 -diol.
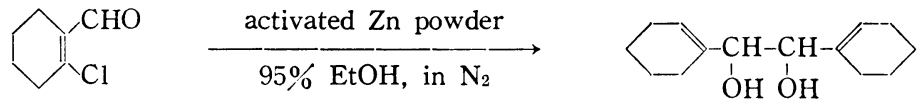

Under the same conditions, the compounds, $\mathbf{3}$ and $\mathbf{4}$, suffered the reductive dimerization to give the analogous compounds, 1,2-bis( $\alpha$-methylstyryl)ethylene glycol (7) and 1,2-di(1cyclopentenyl)ethylene glycol(8), respectively. By the analogy of the compound $\mathbf{6}$, these compounds were identified by noting exact correspondence of their infrared (IR) spectra and by periodic acid color reaction. Comparative data with the reactions with the untreated zinc powder in air are shown in Table II.

In these reactions the olefinic 1,2-diol product is considered to be formed through the intermediate $\alpha, \beta$-unsaturated aldehyde. Selecting $\alpha$-methylcinnamaldehyde as a representative of $\alpha, \beta$-unsaturated aldehyde we treated this compound under the same condition as described in the formation of $\mathbf{7}$ from 3 , but there was observed no formation of $\mathbf{7}$ by this treatment. This reason is considered to be due to the absence of zinc chloride. When $\alpha$-methylcinnamaldehyde was treated with the activated zinc powder-zinc chloride in ethanolic solution in nitrogen atmosphere, $\mathbf{7}$ was obtained in $18 \%$ yield. Under similar conditions, 1 -cyclohexenealdehyde gave 1,2-di(1-cyclohexenyl)ethylene glycol in $48 \%$ yield. Although for reduction of aromatic or $\alpha, \beta$-unsaturated aldehydes to the reductive dimer, olefinic 1,2-diol, there have

5) R.L. Shriner, R.C. Fuson, and D.Y. Curtin, "The Systematic Identification of Organic Compounds," 4 th ed., John Wiley and Sons, Jnc., New York, 1956, p. 129. 
TABLE II. The Reduction ${ }^{a)}$ to 1,2 -Diols

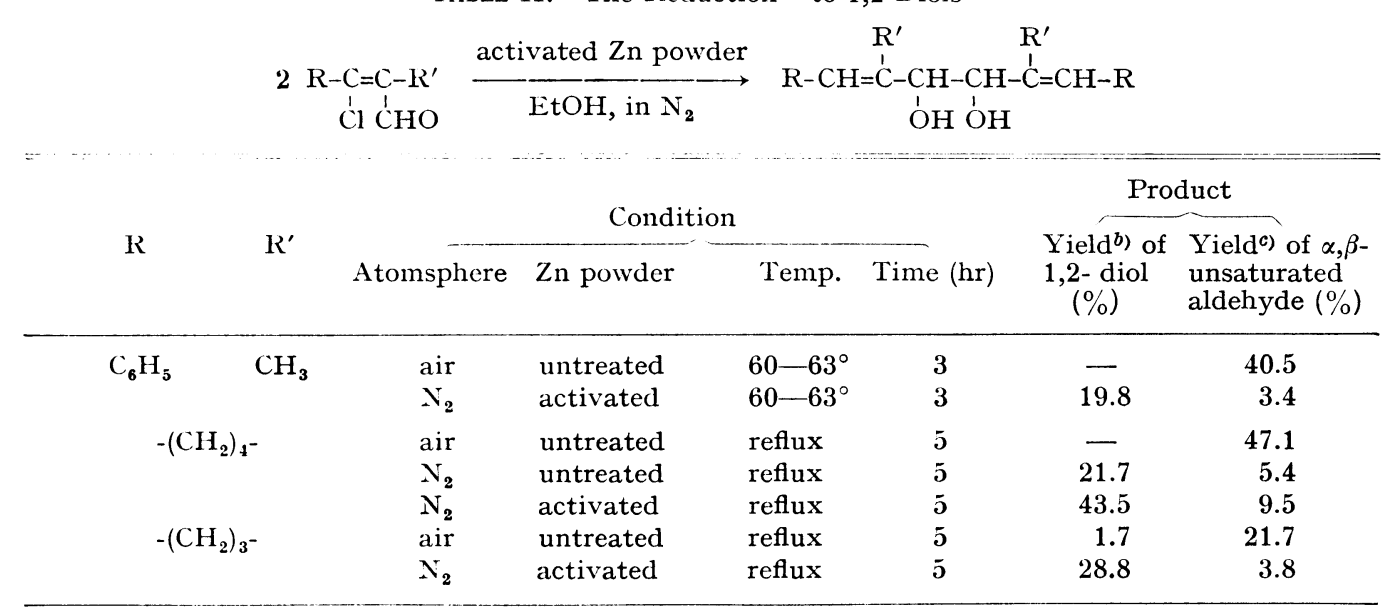

a) Substrate 0.05 mole, zinc powder $0.3 \mathrm{~g}$ atom, and $96.5 \% \mathrm{EtOH}(95 \% \mathrm{EtOH}$ in the cases of 2 -chloro-1-cyclohexenealdehyde) $70 \mathrm{ml}$ were used.

$b$ ) Yield is based on the product actually isolated.

c) Yield is calculated from peak area of gas chromatogrum of the crude distillate of the product.

been known the methods of using several reagents such as sodium or sodium amalgam, $\left.{ }^{6}\right)$ magnesium-magnesium iodide, ${ }^{7)}$ and zinc-copper couple, ${ }^{8)}$ the method of using zinc powderzinc chloride is now recognized to be an easier method for the preparation of the olefinic 1,2diols.

\section{Experimental}

Preparation of $\boldsymbol{\beta}$-Chlorovinylaldehydes_- Four $\beta$-chlorovinylaldehydes, 2-chloro-1-cyclohexenealdehyde, 2 -chloro-1-cyclopentenealdehyde, $\alpha$-methyl- $\beta$-chlorocinnamaldehyde, and $\alpha$ - $n$-pentyl- $\beta$-chlorocrotonaldehyde, were prepared by the reactions of the corresponding ketones with Vilsmeier reagents, dimethylformamide-phosphoryl chloride, mostly according to the method reported by Benson and Pohland. ${ }^{\text {) }}$

To the stirred dimethylformamide $(1.0 \mathrm{~mole})$ cooled on an external ice bath, phosphoryl chloride $(0.8$ mole; was added dropwise. To the stirred mixture was dropwise added the ketone (0.5 mole) and the resulting mixture was controlled under requisite conditions. The reaction mixture was poured onto crashed ice, and neutralized with sodium hydrogen carbonate followed by steam distillation. Usual treatment of the steam distilled oil gave $\beta$-chlorovinylaldehyde, which was carefully distilled under reduced pressure. The four $\beta$-chlorovinylaldehydes are quite unstable and tend to decompose on standing at room temperature. For the reduction the freshly distilled materials were used.

2-Chloro-1-cyclohexenealdehyde: Reaction temperature, room temperature; reaction time, $1 \mathrm{hr}$. bp $85-90^{\circ}(10 \mathrm{mmHg}) \cdot n_{\mathrm{D}}^{20} 1.5204$ [lit.9) bp $86-88^{\circ}(10 \mathrm{mmHg}), n_{\mathrm{D}}^{20} 1.5192$ ]. Yield, $72 \%$, gas chromatographically pure. ${ }^{10)}$ 2,4-Dinitrophenylhydrazone, mp $176.5^{\circ}$ (from AcOEt-trace EtOH) (lit. ${ }^{9}$ mp $178^{\circ}$ ). Anal. Calcd. for $\mathrm{C}_{13} \mathrm{H}_{12} \mathrm{O}_{4} \mathrm{~N}_{4} \mathrm{Cl}: \mathrm{C}, 48.23 ; \mathrm{H}, 3.74 ; \mathrm{N}, 17.31$. Found: C, 48.10; $\mathrm{H}, 4.00 ; \mathrm{N}, 17.63$.

2-Chloro-1-cyclopentenealdehyde: Reaction temperature, room temperature; reaction time, $1 \mathrm{hr}$. bp $74-74.5^{\circ}(15 \mathrm{mmHg}) \cdot n_{\mathrm{D}}^{20} 1.5162$ [lit.9) bp $\left.67-69^{\circ}(12 \mathrm{mmHg}), n_{\mathrm{D}}^{18.5} 1.5163\right]$. Yield, $51.5 \%$ gas chromatographically pure. 2,4-Dinitrophenylhydrazone, $\mathrm{mp} 182.5^{\circ}$ (from AcOEt). Anal. Calcd. for $\mathrm{C}_{12} \mathrm{H}_{11} \mathrm{O}_{4} \mathrm{~N}_{4} \mathrm{Cl}$ : C, $46.39 ; \mathrm{H}, 3.57 ; \mathrm{N}, 18.03$. Found: $\mathrm{C}, 46.59 ; \mathrm{H}, 3.84 ; \mathrm{N}, 18.15$.

6) J. Boeseken and G.H. van Senden, Rec. Trav. Chim., 103, 2213 (1913).

7) R.C. Fuson, E.C. Horning, M.L. Ward, S.P. Rowland, and J.L. Marsh, J. Am. Chem. Soc.,. 64, 30 (1942).

8) W.G. Young, L. Levans, and Z. Jasaitis, J. Am. Chem. Soc., 58, 2274 (1936).

9) W.R. Benson and A.E. Pohland, J. Org. Chem., 30, 1126 (1966).

10) All the gas chromatographic analyses in this work were carried out using Shimazu GC-2B gas chromatograph (detecter: TCD) equipped with $3 \mathrm{~m}$ column (4 mm diameter, packed with Shimazu Thermol-2) and using helium as carrier gas. Column temperature was generally $160^{\circ}$, and the purity or content of product was determined according to the internal normalization method. 
$\alpha$-Methyl- $\beta$-chlorocinnamaldehyde: Reaction temperature, $45-48^{\circ}$; reaction time, $3 \mathrm{hr}$. bp $111-113^{\circ}$ $(4 \mathrm{mmHg}) \cdot n_{\mathrm{D}}^{25} 1.5814$ [lit. ${ }^{2 b)}$ bp $117^{\circ}(1.2 \mathrm{mmHg}), n_{\mathrm{D}}^{20} 1.5833$ ]. Yield, $69 \%$, gas chromatographically pure. 2,4-Dinitrophenylhydrazone, $\mathrm{mp} 188^{\circ}$ (from AcOEt-trace $\mathrm{EtOH}$ ). Anal. Calcd. for $\mathrm{C}_{16} \mathrm{H}_{13} \mathrm{O}_{4} \mathrm{~N}_{4} \mathrm{Cl}: \mathrm{C}, 53.27$; $\mathrm{H}, 3.63 ; \mathrm{N}, 15.53$. Found: C, 53.14; H, 3.53; N, 15.69. Semicarbazone, $\mathrm{mp} 154^{\circ}\left(\right.$ lit. $^{2 b)} \mathrm{mp} 154-155^{\circ}$ ).

$\alpha$-n-Pentyl- $\beta$-chlorocrotonaldehyde: Reaction temperature, $45-50$; reaction time, $1.5 \mathrm{hr}$. bp $67-71^{\circ}$ $(2 \mathrm{mmHg})$, approximately $80 \%$ purity on gas chromatography, yicld, $50 \%$. The repeated redistillations under reduced pressure effected almost no enrichment of the product and gave considerable amount of dark brown pot residues on every runs of the distillations, indicating occurrence of remarked decompositions of the product during the distillations. The above-obtained final center cut was used for the following reduction without any further purification. 2.4-Dinitrophenylhydrazone, mp $174.5^{\circ}$ (from AcOEt-trace EtOH). Anal. Calcd. for $\mathrm{C}_{15} \mathrm{H}_{19} \mathrm{O}_{4} \mathrm{~N}_{4} \mathrm{Cl}$ : C, 50.78; H, 5.40; N, 15.79. Found: C, 50.99; H, $5.31 ; \mathrm{N}, 15.80$.

Reduction of $\beta$-Chlorovinylaldehydes with Zinc Powder in Ethanol

1-Cyclohexenealdehyde-A mixture of $7.3 \mathrm{~g}(0.05$ mole) of 2-chloro-1-cyclohexenealdehyde, $29.43 \mathrm{~g}$ $(0.45 \mathrm{~g} \cdot$ atom) of zinc powder and $70 \mathrm{ml}$ of $96.5 \%$ ethanol was refluxed with vigorous stirring on a boiling water bath for $2.5 \mathrm{hr}$. The reaction mixture was filtered and the filtrate was evaporatcd to approximately $30 \mathrm{ml}$. The concentrate was poured into water and extracted with ether. The ethereal layers were washed with a small amount of water and dried over $\mathrm{MgSO}_{4}$. After removal of the drying agent and ether, the a residual liquid was distilled under reduced pressure and the whole distillate, crude product, was collected in receiver cooled in a dry ice-acetone bath. Content of 1-cyclohexenealdehyde was measured by gas chromatographic analysis. Yield, $65 \%$. Redistillation of the crude oil gave pure 1-cyclohexenealdehyde, bp $63-67^{\circ}(11 \mathrm{mmHg}) \cdot n_{\mathrm{D}}^{30.5} 1.4900$ [lit. $\left.{ }^{11)} \mathrm{bp} 60-61^{\circ}(11 \mathrm{mmHg}) . n_{\mathrm{D}}^{19} 1.4929\right]$. The 2,4-dinitrophenylhydrazo ne was prepared, $\mathrm{mp} 217.5^{\circ}$ (from AcOEt) (lit. ${ }^{12}$ mp 217-218 ${ }^{\circ}$ ). Anal. Calcd. for $\mathrm{C}_{13} \mathrm{H}_{14} \mathrm{O}_{4} \mathrm{~N}_{4}: \mathrm{C}_{2} 53.79$; $\mathrm{H}, 4.86 ; \mathrm{N}, 19.30$. Found: C, $53.89 ; \mathrm{H}, 4.99 ; \mathrm{N}, 19.45$.

$\alpha$-Methylcinnamaldehyde-A mixture of $9 \mathrm{~g}(0.05$ mole $)$ of zinc powder, and $70 \mathrm{ml}$ of $96.5^{\prime \prime}$, ethanol was vigorously stirred at $60-63^{\circ}$ for $1.5 \mathrm{hr}$. After filtration, the filtrate was concentrated to approximately $30 \mathrm{ml}$, poured into water and extracted with ether. The ethereal layer was washecl with a small amount of water and dried over $\mathrm{MgSO}_{4}$. After removal of the solids and ether, the residual liquid was distilled on an oil bath under reduced pressure to give crude oil. The gas chromatographic analysis indicated that this liquid consists of $61.84 \%$ of $\alpha$-methylcinnamaldehyde $(49.2 \%$ yield). Redistillation furnished pure product, bp $139-140^{\circ}(26 \mathrm{mmHg}) . n_{\mathrm{D}}^{25} 1.6002$ (lit. ${ }^{12)}$ bp $\left.148-149^{\circ}(27 \mathrm{mmHg}), n_{\mathrm{D}}^{17.0} 1.6057\right)$, which showed single peak on gas chromatography, and its retention time was in agreement with that of an authentic $x$-methylcinnamaldehyde. The semicarbazone was prepared, mp $207^{\circ}$ (from $50 \%$ ethanol) (lit. ${ }^{13}$ ) $\mathrm{mp} 20 \overline{7}-208^{\circ}$ ). Anal. Calcd. for $\mathrm{C}_{11} \mathrm{H}_{13} \mathrm{ON}_{3}: \mathrm{C}, 65.00 ; \mathrm{H}, 6.45 ; \mathrm{N}, 20.68$. Found: C, 64.93; H, 6.57; N, 20.90. The semicarbazone gave no melting point depression on admixture with an authentic sample.

1-Cyclopentenealdehyde_- A mixture of $6.53 \mathrm{~g}(0.05 \mathrm{molc})$ of 2-chloro-1-cyclepentencaldehyde, 29.42 $\mathrm{g}$ $(0.45 \mathrm{~g} \cdot$ atom) of zinc powder, and $70 \mathrm{ml}$ of $96.5 \%$ ethanol was vigorously stirred under reflux for $1 \mathrm{hr}$. The reaction mixture was worked up in the same manner as described in the case of 1-cyclohexenealdehyde to give the crude distillate which was shown to contain $81.38 \%$ (yield $37.3 \%$ ) of 1 -cyclopentenealdehyde by gas chromatographic analysis. Redistillation afforded the pure product, bp $71-72^{\circ}(42 \mathrm{mmHg})$, which showed single peak of 1 -cyclopentenealdehyde on gas chromatography, $n_{\mathrm{D}}^{24.3} 1.4850, n_{\mathrm{D}}^{25} 1.4866\left[\mathrm{lit}^{13}\right) \mathrm{bp} 48^{\circ}(11 \mathrm{mmHg})$, $n_{\mathrm{D}}^{21}$ 1.4828]. The 2,4-dinitrophenylhydrazone was prepared, mp $212^{\circ}$ (from AcOEt) (lit. ${ }^{14)} \mathrm{mp} 216^{\circ}$ ). Anal. calcd. for $\mathrm{C}_{12} \mathrm{H}_{12} \mathrm{O}_{4} \mathrm{~N}_{4}: \mathrm{C}, 52.17 ; \mathrm{H}, 4.38 ; \mathrm{N}, 20.28$. Found: $\mathrm{C}, 51.72 ; \mathrm{H}, 4.35 ; \mathrm{N}, 20.46$. The semicarbazone was also prepared, $\mathrm{mp} 207.5^{\circ}$ (decomp.) (from $50 \%$ ethanol) (lit. ${ }^{15)} \mathrm{mp} 208^{\circ}$ ). Anal. Calcd. for $\mathrm{C}_{7} \mathrm{H}_{11} \mathrm{ON}_{3}$ : C, $54.88 ; \mathrm{H}, 7.24 ; \mathrm{N}, 27.43$. Found: C, $54.88 ; \mathrm{H}, 7.00 ; \mathrm{N}, 27.07$. The pasty pot residue obtained in the foregoing distillation contained a minute amount of crystalline substance, which was isolated by scratching with petroleum ether. The crystals, $0.05 \mathrm{~g}$, were collected by filtration and the recrystallization from benzeneethanol mixture gave plates, $\mathrm{mp} 124.5^{\circ}$. The crystal showed positive periodic acid color reaction ${ }^{5)}$ and was proved to be 1,2-di(1-cyclopentenyl)ethylene glycol. Anal. Calcd. for $\mathrm{C}_{12} \mathrm{H}_{18} \mathrm{O}_{2}: \mathrm{C}, 74.19 ; \mathrm{H}, 9.34$. Found: C, 73.97; H, 9.14. IR $v_{\max }^{\mathrm{KBr}}\left(\mathrm{cm}^{-1}\right): 3400,1140,1636,830$.

$\boldsymbol{a}$ - $\boldsymbol{n}$-Pentylcrotonaldehyde-A mixture of $8.73 \mathrm{~g}(0.04$ mole as $80 \%$ purity) of $\alpha$-n-pentyl- $\beta$-chlorocrotonaldehyde, $23.4 \mathrm{~g}(0.36 \mathrm{~g}$ atom) of zinc powder and $60 \mathrm{ml}$ of $96.5 \%$ ethanol was refluxed on a boiling water bath with vigorous stirring for $3 \mathrm{hr}$. The reaction mixture was worked up in the same manner as described in the case of 1-cyclohexenealdehyde to give the crude oil by the distillation under reduced pressure. The oil was shown to contain $78.47 \%(42 \%$ yield) of $\alpha$-n-pentylcrotonaldehyde by gas chromatographic analysis. Redistillation gave gas chromatographically pure $\alpha$-n-pentylcrotonaldehyde, bp $70^{\circ}(8 \mathrm{mmHg}), n_{\mathrm{D}}^{26.5} 1.4498$ [lit. ${ }^{16)}$ bp $\left.57-59^{\circ}(3 \mathrm{mmHg}), n_{\mathrm{D}}^{20} 1.45362\right]$. The 2,4-dinitrophenylhydrazone was prepared, $\mathrm{mp} 151^{\circ}$ (from

11) W. Surber, V. Theus, L. Colombi, and H. Schinz, Helv. Chim. Acta, 39, 1299 (1956).

12) L. Roos, R.W. Goetz, and M. Orchin, J. Org. Chem. 30, 3023 (1965).

13) K.V. Auwers, Chem. Ber., 45, 2777 (1912).

14) "Chemistry of Carbon Compounds," II-A, ed. by E.H. Rodd, Elsevier Publishing Company, 1953 p. 92.

15) A. Baeyer and H. von Liebig, Chem. Ber., 31, 2108 (1898).

16) B. Zaar, Ber. Schimmel Co., Akt. Gcs., 1929, 311 [C. A., 24, 21074 (1930)]. 
AcOEt-trace EtOH). Anal. Calcd. for $\mathrm{C}_{15} \mathrm{H}_{20} \mathrm{O}_{4} \mathrm{~N}_{4}: \mathrm{C}, 56.24 ; \mathrm{H}, 6.29 ; \mathrm{N}, 17.49$. Found: $\mathrm{C}, 56.61 ; \mathrm{H}$, $6.54 ; \mathrm{N}, 17.31$. The semicarbazone was also prepared, $\mathrm{mp} 151^{\circ}$ (from AcOEt-trace EtOH). Anal. Calcd. for $\mathrm{C}_{15} \mathrm{H}_{20} \mathrm{O}_{4}: \mathrm{C}, 56.24 ; \mathrm{H}, 6.29 ; \mathrm{N}, 17.49$. Found: C, 56.61; H, 6.54; N, 17.31. The semicarbazone was also prepared, $\operatorname{mp} 168^{\circ}$ (lit. ${ }^{15)} \mathrm{mp} 168-168.5^{\circ}$ ).

Reduction of $\boldsymbol{\beta}$-Chlorovinylaldehydes with Activated Zinc Powder in Ethanol in Nitrogen Atmosphere

1,2-Di(1-cyclohexenyl)ethylene Glycol-A mixture of $7.4 \mathrm{~g}(0.05 \mathrm{~mole})$ of 2-chloro-1-cyclohexenealdehyde, $19.62 \mathrm{~g}(0.30 \mathrm{~g}$ atom) of zinc powder, which was activated by stirring with $50 \mathrm{ml}$ of $5 \%$ hydrochloric acid for few minutes and succeedingly washing with water and ethanol, and $70 \mathrm{ml}$ of $95 \%$ ethanol was vigorously stirred under reflux in nitrogen atmosphere for $5 \mathrm{hr}$. The reaction mixture was filtered and the filtrate was evaporated to approximately $40 \mathrm{ml}$. The concentrate was poured into water and extracted with ether. The ethereal solution was dried over $\mathrm{MgSO}_{4}$. After removal of the drying agent and ether, deposited 1,2-di(1-cyclohexenyl)ethylene glycol was collected by filtration, and washed with a small amount of petroleum ether. The crystals, $\mathrm{mp} 78^{\circ}$, weighed $2.4 \mathrm{~g}\left(43.5 \%\right.$ yield). IR $v_{\max }^{\mathrm{KBr}}\left(\mathrm{cm}^{-1}\right): 3450,1040,1665$, 840. $\operatorname{XYR}\left(\tau\right.$ in $\left.\mathrm{CDCl}_{3}\right): 8.7-7.7(16 \mathrm{H}$, multiplet, cyclohexene ring protons), $7.64(2 \mathrm{H}$, singlet, $>\mathrm{CHOH}$; disappeared by addition of heavy water), $6.1(2 \mathrm{H}$, singlet, $-\mathrm{CH}-), 4.4-4.1(2 \mathrm{H}$, multiplet, $\mathrm{CH}=\mathrm{C})$. Anal. Calccl. for $\mathrm{C}_{14} \mathrm{H}_{22} \mathrm{O}_{2}: \mathrm{C}, 75.63: \mathrm{H}, 9.97$. Found: $\mathrm{C}, 75.60 ; \mathrm{H}, 9.73$. The crystals had positive periodic acid color reaction. ${ }^{5}$ After removal of the solvent from the foregoing filtrate, the residual oil was distilled under reduced pressure to give 1 -cyclohexenealdehyde in $9.5 \%$ yield, amount of which was determined by gas chromatographic analysis.

When the untreated zinc powder was employed in the above experiment, the 1,2-diol was obtained in $21 \%$ yield and 1-cyclohexencaldehyde in $6 \%$ yield.

When carried out this reaction in air, no 1,2-diol was obtained but 1-cyclohexenealdehyde was obtained in $47^{\circ}, 0$ yield.

1.2-Di(1-cyclopentenyl)ethylene Glycol_-Obtained according to the same procedures as described in the above experiment except that $96.5 \%$ ethanol was used in place of $95 \%$ ethanol. Yield, $28.9 \%$. This crystal, mp $124^{\circ}$, showed no melting point depression on admixture with the 1,2-diol obtained in the foregoing experiment, and further these IR data were in full agreement with each other. 1-Cyclopentenealdehyde was obtained in $0.6 \%$ yield.

1,2-Bis $(\alpha$-methylstyryl)ethylene Glycol___Obtained according to the same procedures as described in the above experiment, but the reaction was carried out at $60-63^{\circ}$ for $3 \mathrm{hr}$. The crystals, $\mathrm{mp} 174^{\circ}$, were obtained in $19.8 \%$ yield. Il $v_{\max }^{\mathrm{KBr}}\left(\mathrm{cm}^{-1}\right): 3500,1000,750,705$. This material had positive periodic acid color reaction. ${ }^{5}$ Anal. Calcd. for $\mathrm{C}_{20} \mathrm{H}_{22} \mathrm{O}_{2}: \mathrm{C}, 81.60 ; \mathrm{H}, 7.53$. Found: C, 81.64; H, 7.59. $\alpha$-Methylcinnamaldehyde was obtained in $3.4 \%$ yield.

Reaction of $\alpha, \beta$-Unsaturated Aldehydes with Zinc Powder-Zinc Chloride in Ethanol and the Related Reactions

$\alpha$-Methylcinnamaldehyde_- A mixture of $7.3 \mathrm{~g}(0.05 \mathrm{~mole})$ of $\alpha$-methylcinnamaldehyde, $19.62 \mathrm{~g}(0.30 \mathrm{~g}$ atom) of zinc powder freshly activated, $6.8 \mathrm{~g}(0.05$ mole) of zinc chloride and $70 \mathrm{ml}$ of $96.5 \%$ ethanol was heated at $60-62^{\circ}$ for $3 \mathrm{hr}$ with vigorous stirring in nitrogen atmosphere. The reaction mixture was filtered and after standing overnight, deposited crystals were collected by filtration, washed with water and dried. The extract of the solids by refluxing with benzene afforded $1.25 \mathrm{~g}$ (17\% yield) of 1,2-bis( $\alpha$-methylstyryl)ethrlene glycol, $\mathrm{mp} 174^{\circ}$, which showed no melting point depression on admixture with a specimen of 1,2 -bis( $x$-methylstyryl)ethylene glycol obtained in the foregoing experiment. The foregoing alcoholic filtrate was concentrated and the concentrate was poured into water, extracted with ether and dried. Concentration of the drid ethereal extract gave additional $0.05 \mathrm{~g}$ (yield, $0.7 \%$ ) of the 1,2-diol. Vacuum distillation of the residual oil obtained by removal of crystals gave a small amount of the crude oil which was shown to contain the unchanged $\alpha$-methylcinnamaldehyde and a number of byproducts, which were detected by gas chromatography.

The absence of zinc chloride in the above reaction afforded $76.7 \%$ yield of the unchanged aldehyde and $1.8 \%$ yield of 1,2 -bis $(\alpha$-methylstyryl)ethylene glycol.

When carried out in air by using the untreated zinc powder in the absence of zinc chloride, the starting $\alpha$-methylcinnamaldehyde was recovered in $79.5 \%$ yield and no crystalline material was obtained.

1-Cyclohexenealdehyde_-A mixture of $3.3 \mathrm{~g}(0.03 \mathrm{~mole})$ of 1 -cyclohexenealdehyde, $11.7 \mathrm{~g}(0.18 \mathrm{~g}$ atom) of zinc powder freshly activated, $4.0 \mathrm{~g}(0.03$ mole) of zinc chloride and $70 \mathrm{ml}$ of $96.5 \%$ ethanol was refluxed for $3 \mathrm{hr}$ with vigorous stirring in nitrogen atmosphere. The reaction mixture was filtered and the filtrate was poured into water and extracted with ether. The ethereal solution was washed with a small amount of water and dried over $\mathrm{MgSO}_{4}$. Removal of the drying agent and ether afforded $1.6 \mathrm{~g}(48 \%$ yield) of 1,2-di(1-cyclohexenyl)ethylene glycol, $\mathrm{mp} 75^{\circ}$, which was recrystallized from petroleum ether to prisms, $\mathrm{mp} 78^{\circ}$. The IR spectrum was in full agreement with that of 1,2-di(1-cyclohexenyl)ethylene glycol obtained from 2-chloro-1-cyclohexenealdehyde in the foregoing experiment.

Acknowledgement We are grateful to the members of Analytical Center of this college for their elemental analysis and spectral measurements. 